\title{
Hot topic: Milk and plasma disposition of thymol following intramammary administration of a phytoceutical mastitis treatment
}

\author{
C. S. McPhee, ${ }^{\star}$ K. L. Anderson, ${ }^{\star}$ J. L. Yeatts, $†$ S. E. Mason,‡ B. M. Barlow, $†$ and R. E. Baynes ${ }^{\star} \dagger^{1}$ \\ *Department of Population Health and Pathobiology, and \\ †Center for Chemical Toxicology Research and Pharmacokinetics, College of Veterinary Medicine, North Carolina State University, Raleigh 27606 \\ ‡Department of Biological Sciences, Campbell University, Buies Creek, NC 27506
}

\begin{abstract}
Despite the recent growth of the organic dairy industry, organic producers and veterinarians have limited information when choosing mastitis treatments for animals in organic dairy production. Organic producers commonly administer homeopathic or other plantbased products without having research evaluating the efficacy of these products and using estimated or no withholding times to treat mastitis and other health problems in their herds. In this pilot study, we attempted to identify several active ingredients of Phyto-Mast (Penn Dutch Cow Care, Narvon, PA), a plant-based mastitis treatment used on organic dairy farms, and to quantify the product residue in milk and plasma after intramammary administration. We developed an assay to quantify thymol (one of the active ingredients in Phyto-Mast) in milk and plasma using gas chromatography and mass spectrometry (GC-MS). Thymol is a volatile aromatic compound with antiinflammatory properties. As a model for dairy cows, 5 healthy, lactating alpine dairy goats were given $5 \mathrm{~mL}$ of Phyto-Mast per udder half. For $10 \mathrm{~d}$ following treatment, we analyzed blood and milk samples for thymol residues using GC-MS. The GC-MS assay was very sensitive for thymol detection, to a concentration of $0.01 \mu \mathrm{g} / \mathrm{mL}$ in plasma. Using thymol as a marker, Phyto-Mast was detectable and quantifiable in plasma beginning with the 15-min posttreatment sample, but was no longer detectable in the 4-h posttreatment sample. Thymol residues were only detected in the 12-h posttreatment milk sample. An inflammatory response was not evident in the udder following phytoceutical administration. Although this study provides information about the elimination of thymol, the product contains several other active chemicals, which may have different pharmacokinetic behaviors. Further analysis and additional study animals will help to determine a milk withholding time
\end{abstract}

Received November 4, 2010.

Accepted February 1, 2011.

${ }^{1}$ Corresponding author: Ronald_Baynes@ncsu.edu for Phyto-Mast. Given the recent growth of the organic dairy industry, understanding the pharmacokinetics of therapeutics used in organic production and developing accurate withholding recommendations will help to ensure milk safety.

Key words: Phyto-Mast, organic production, thymol, mastitis treatment

\section{INTRODUCTION}

In recent years, the organic dairy industry has undergone tremendous growth (International Federation of Organic Agriculture Movements, 2008). As seen on conventional dairies, the cows on organic dairy farms are susceptible to common mastitis infections. Because the United States Department of Agriculture National Organic Standards Board (USDA-NOSB) does not allow use of antibiotics in US organic herds, veterinarians and producers resort to using nonantibiotic alternatives (USDA-Agricultural Marketing Service, 2010).

Nutraceuticals are products derived from food or nutrients that are used in a therapeutic capacity. Phytoceuticals are nutraceuticals derived primarily from plant material. Although the use of unapproved products is against FDA recommendations (Ruegg, 2009), some organic producers treat mastitis in their herds with a product, such as a phytoceutical, that does not contain substances prohibited by the USDA-NOSB. Anecdotal reports indicate that phytoceutical products can be effective in treating mastitis (Karreman, 2007). The route of administration, dosage, and withdrawal times for such protocols are based primarily on inference from human data, clinical experience, or speculation. Organic and conventional dairy products are subject to identical regulatory testing, including screening for SCC and residues of $\beta$-lactam antibiotics.

Our hypothesis was that intramammary (IMM) administration of a phytoceutical mastitis treatment would result in milk and plasma residues detectable by GC-MS analysis. The objective of this study was to evaluate the mammary gland response and to quantify residues of one or more of the active chemical com- 
Table 1. Phytoceutical mastitis treatment ingredients, major chemical components, and bioactivity in PhytoMast (Penn Dutch Cow Care, Narvon, PA)

\begin{tabular}{llll}
\hline Ingredient & Common name & Active chemical & Bioactivity \\
\hline Thymus vulgaris & Garden thyme & Thymol & Antiinflammatory, antiseptic \\
Gaultheria procumbens & Oil of wintergreen & Methyl salicylate & Analgesic, antipyretic \\
Glycyrrhiza uralensis & Chinese licorice & Glycyrrhizin & Antiinflammatory, demulcent \\
Angelica sinensis & Chinese angelica & $\alpha$-Pinene & Antiinflammatory, circulatory stimulant \\
\hline
\end{tabular}

ponents in milk and plasma samples following IMM administration of a phytoceutical product used for mastitis treatment.

\section{MATERIALS AND METHODS}

\section{Animals and Treatment}

This research was conducted at the North Carolina State University Metabolism Educational Unit and at the College of Veterinary Medicine, Raleigh, North Carolina. All research was approved by the NC State University Institutional Animal Care and Use Committee.

Five healthy alpine or alpine-cross dairy goat does in late lactation (average age: $4.5 \mathrm{yr}$, range $4-5 \mathrm{yr}$ ) were used in this study as a model for dairy cows. Based upon clinical examination, evaluation of milk samples by California Mastitis Test (CMT), and aerobic microbiology with identification of pathogens performed on aseptically collected milk samples, the does were confirmed as being free from evidence of mastitis (Hogan et al., 2005). Two goats were studied in July 2009 and 3 additional does in February 2010. The does were fed approximately $1 \%$ of BW per day of a complete pelleted goat feed with 17\% CP (17\% Goat Feed, Southern States Cooperative Inc., Richmond, VA), with a hay mixture (25\% alfalfa and $75 \%$ orchard grass) ad libitum. The does had 1 wk to adapt to the study site before sampling and treatment. All animals were milked by hand twice daily throughout the study period, and milk production was recorded.

Baseline milk and plasma samples were collected pretreatment to determine the background levels of active components. The teat ends were carefully prepared by teat dipping in a 1\% iodine solution (Bovadine Sanitizing Teat Dip, West Agro Inc., Kansas City, MO) and wiping with a clean paper towel. The teat ends were then scrubbed with alcohol-soaked cotton balls, and 5 $\mathrm{mL}$ of the phytoceutical (Phyto-Mast, Penn Dutch Cow Care, Narvon, PA) was administered via IMM infusion into each udder half of all study goats. The phytoceutical has been approved by an accredited organic certifying agent, the Ohio Ecological Food and Farm
Association, as a safe product for mastitis treatment, and does not contain any substances prohibited by the USDA-NOSB (Kentucky State University Organic Agricultural Working Group, 2009; USDA-Agricultural Marketing Service, 2010). The components of the phytoceutical mastitis treatment are listed in Table 1.

The phytoceutical is packaged in a $12-\mathrm{mL}$ tube, and 1 full tube is intended for 1 quarter of a cow. The decision to administer $5 \mathrm{~mL}$ per udder half was based upon consideration of the smaller size of the goat udder. Following administration of the phytoceutical, the does' mammary glands were monitored closely by physical examination and CMT repeated at each milking. The does were also given an overall physical examination at every twice-daily milking following treatment for 4 d. Physical examinations included evaluation of mental status, rectal temperature, heart rate, respiratory rate, ruminal contractions, and palpation of mammary glands.

\section{Sample Collection}

Before dosing, 14-cm, 16-gauge catheters (Angiocath, BD Worldwide, Franklin Lakes, NJ) were placed intravenously in a jugular vein of each doe. Following IMM administration of PhytoMast, blood samples were collected in heparinized blood tubes (plasma tube with lithium heparin, BD Worldwide) from each doe at 15 , 30 , and $60 \mathrm{~min}$ and then at 2, 4, 8, 24, 36, and $48 \mathrm{~h}$ following IMM treatment. We collected blood samples from the 2 initial does for $10 \mathrm{~d}$ following treatment, and based upon results, for $3 \mathrm{~d}$ following treatment for the subsequent group. The blood samples were centrifuged at $1,500 \times g$ for 15 min. Plasma was aspirated and placed in 7-mL polypropylene tubes (Sarstedt AG \& Co, Newton, NC). One milliliter was removed, placed into a $10-\mathrm{mL}$ solid-phase microextraction vial, and sealed with a cap containing a silicone septum (Supelco Analytical, Sigma Aldrich International, Bellefonte, PA). Each udder half was hand-milked separately into a clean stainless-steel bucket, and milk production was measured by weight using a laboratory gram scale, and by volume in a graduated cylinder. Milk samples were collected from pooled milk from each udder half 
at milkings every $12 \mathrm{~h}$ following treatment into $15-\mathrm{mL}$ centrifuge tubes. Statistical analysis of milk production before and after phytoceutical administration was evaluated with an ANOVA model (Stata v10.0, Stata Corp., College Station, TX).

\section{Analytical Chemistry}

We initially determined the major chemical components of all 4 active ingredients in Phyto-Mast and attempted to identify retention peaks for each of them using GC with the headspace method. Only thymol and methyl salicylate had identifiable peaks, and only thymol was readily detectable at very low concentrations. We therefore developed an assay to detect thymol, the primary component of garden thyme, in milk and plasma samples. To extract and analyze the chemical residue, we used a GC-MS [Varian CP-3800 GC/2200 MS coupled with solid-phase microextraction (SPME) equipped Combi-PAL autosampler; Varian Inc., Agilent Technologies, Santa Clara, CA]. To detect thymol in the samples, a $100-\mu \mathrm{m}$ polydimethylsiloxane (PDMS) SPME fiber was preconditioned as recommended by the manufacturer (Supelco Analytical). The 1-mL biological samples and standards in sealed 10-mL vials were heated to $37^{\circ} \mathrm{C}$ and agitated continuously at $500 \mathrm{rpm}$ for $5 \mathrm{~min}$ to equilibrate gaseous and liquid phases of the chemicals. Following agitation, the PDMS fiber was inserted into the headspace of the sample vial and exposed for 20 min with the vial temperature held static at $37^{\circ} \mathrm{C}$ for extraction of the chemicals. After exposure, the fiber was desorbed for $2 \mathrm{~min}$ in the injection port of the GC-MS.

Purified chemical standards of thymol (CAS 89-83-8, item no. 16254, Sigma-Aldrich International, St. Louis, MO) and methyl salicylate (Reagent Plus, CAS 119-368, item no. M6752, Sigma-Aldrich International) in media (goat plasma and milk from pretreatment animals) were used to create a standard curve for quantification and calculate concentration present in samples. The temperature of injection port was maintained at $280^{\circ} \mathrm{C}$ and the chromatographic separations were performed using a capillary column $(30 \mathrm{~m} \times 0.25 \mathrm{~mm}$ i.d. $\times 0.25$ $\mu \mathrm{m}$ film, Agilent Technologies, Santa Clara, CA) with a 0.75-mm SPME liner (Siltek ID SPME Liner, Restek, Bellefonte, PA). The column oven programming began at an initial temperature of $40^{\circ} \mathrm{C}$ held for $3 \mathrm{~min}$, and then increased at $30^{\circ} \mathrm{C} / \mathrm{min}$ to $280^{\circ} \mathrm{C}$. From the time of desorption in the injection port, the total time in the GC-MS was 18 min (Vijay et al., 2007). A constant flow of $1 \mathrm{~mL} / \mathrm{min}$ was maintained with a pressure of $144.79 \mathrm{kPa}$, using helium as the inert carrier gas. Limit of detection (LOD) and limit of quantification (LOQ) for milk and plasma were calculated using the signal-to- noise ratio method (Snyder et al., 1997). We considered the LOD to be the lowest level at which the concentration of thymol could be differentiated from a blank sample (containing no thymol) and the LOQ to be the concentration at which the analyte could be identified with adequate precision under the study conditions. We used the GC-MS and its software for all sample analysis and assay development (Varian MS Workstation version 6.5, Varian Inc.). Noncompartmental analysis was attempted with WinNonLin 6.0 (Pharsight Inc., Mountain View, CA).

\section{RESULTS}

Following IMM administration of the phytoceutical product, the animals displayed no clinical signs of illness, and their vital signs, as assessed by the physical examination described earlier, remained within normal limits. The product appeared nonirritating, as the SCC as assessed by CMT did not increase in any of the does posttreatment. No perceptible change in udder conformation was observed, and all aseptically collected milk samples remained culture negative. Daily average milk production per doe was approximately $1 \mathrm{~L}$ for the 2 initial does and $1.7 \mathrm{~L}$ for the other 3 does. Milk production did not change following IMM treatment based on statistical comparison of milk production before and after treatment.

Essential oil of garden thyme is one of the active ingredients in the phytoceutical mastitis treatment because of its antiseptic properties (Karreman, 2007; Wynn and Fougère, 2007). The primary chemical component of garden thyme is thymol, which was readily detectable using the headspace assay with a retention time of $7.4 \mathrm{~min}$. For plasma samples, the calculated LOD of thymol was $0.01 \mu \mathrm{g} / \mathrm{mL}$, and the LOQ was $0.05 \mu \mathrm{g} / \mathrm{mL}$. For milk samples, the calculated LOD was $0.05 \mu \mathrm{g} / \mathrm{mL}$, and the LOQ was $0.075 \mu \mathrm{g} / \mathrm{mL}$. Methyl salicylate had a retention time of $7.0 \mathrm{~min}$ using purified chemical standards. However, methyl salicylate was not readily detectable in any of the milk or plasma samples by means of the headspace assay.

Using the SPME headspace method, we detected thymol in plasma samples beginning at 15 -min posttreatment, as demonstrated in Figure 1. One animal did not have blood taken at the 15-min posttreatment time point because of a catheter problem. Maximum plasma levels were detected in the 30-min posttreatment sample. By $2 \mathrm{~h}$ posttreatment, levels of thymol were below the LOQ for all samples, and by the 4-h posttreatment sample were below the LOD.

As Figure 2 demonstrates, thymol was detected in the 12-h milk samples in all but one udder half. Apart from trace concentrations $(0.1 \mu \mathrm{g} / \mathrm{mL})$ found in one 


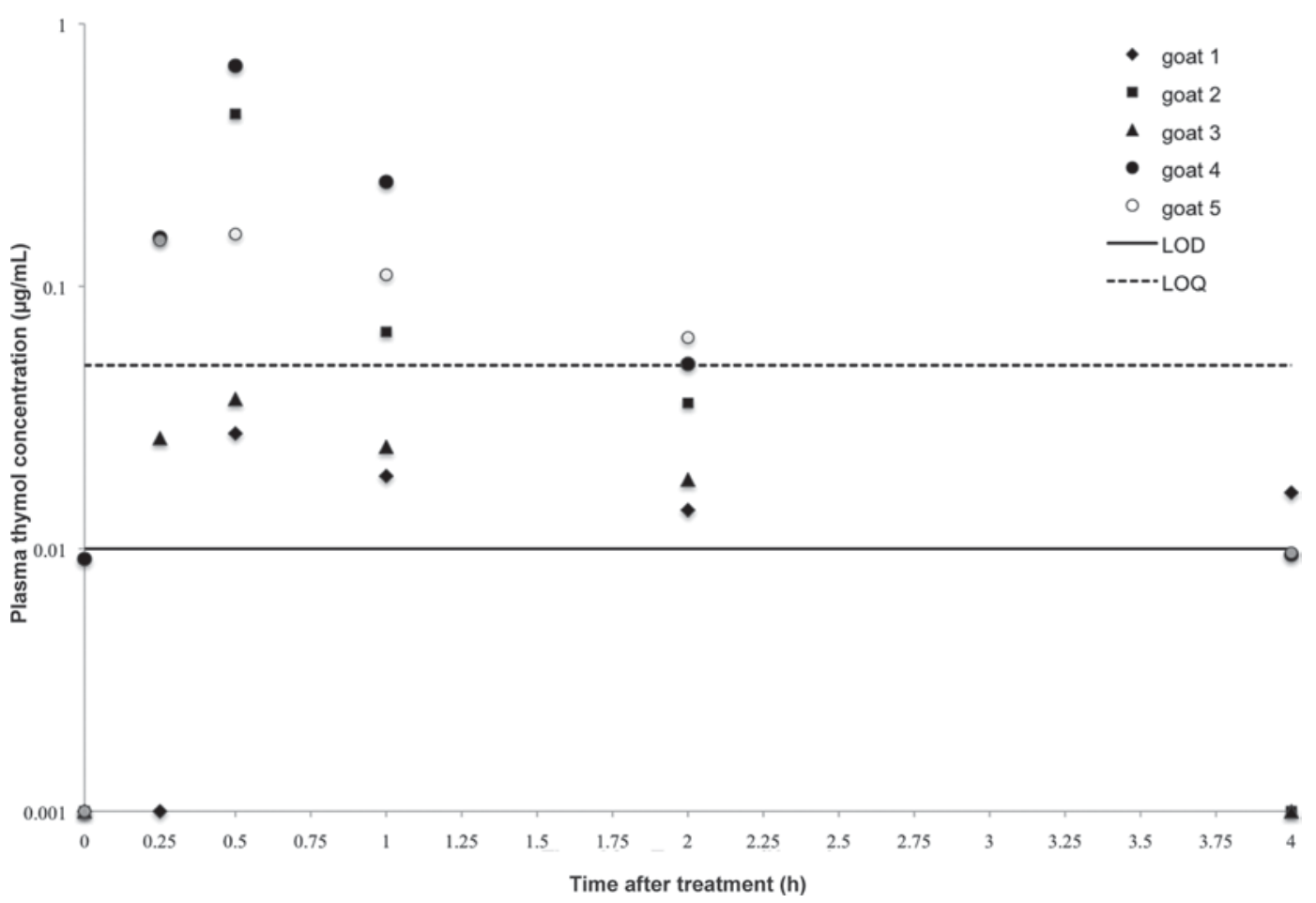

Figure 1. Plasma thymol concentration following intramammary administration (logarithmic scale). For each of the 5 study animals, the plasma concentration of thymol in parts per million is plotted on the $\mathrm{y}$-axis. The $\mathrm{x}$-axis is time following phytoceutical administration. The limit of detection $(0.01 \mu \mathrm{g} / \mathrm{mL})$ is indicated by the solid black line, and the limit of quantification $(0.05 \mu \mathrm{g} / \mathrm{mL})$ is indicated by the dotted black line. The plasma concentrations peaked in the 30-min posttreatment sample, and all samples were below the limit of quantification by $4 \mathrm{~h}$ posttreatment.

24-h sample from one udder half, subsequent samples did not contain thymol residues.

Compartmental and noncompartmental pharmacokinetic analysis was not successful because of the limited data sets for each animal. Subsequent apparent half-life is not available.

\section{DISCUSSION}

Organic dairy producers in the United States face challenges when dealing with sick cows. Treatment must not be withheld from sick animals, but very few options are available for approved treatments of conditions such as mastitis (USDA-Agricultural Marketing Service National Organic Program, 2008). Phytoceutical products have become available for treatment of mastitis; however, little information is available concerning their efficacy or withholding times. As long as these products continue to be sold and used, it is important to investigate their biological and pharmacokinetic behavior. Understanding the pharmacokinetics of active ingredients used in dairy production will lead to accurate withholding recommendations and improved organic milk safety.

We are not aware of previously published research addressing the pharmacokinetic activities of masti- tis treatments used in organic dairy herds. Our data from this pilot project indicate that, using thymol as a marker, it is possible to trace a phytoceutical mastitis treatment in both milk and plasma. In our study animals, we found that administration of this phytoceutical product results in minimal plasma and milk residues of thymol, which become undetectable after $12 \mathrm{~h}$. The data are insufficient to determine an apparent half-life of thymol. A more accurate determination of half-life would require intravenous administration of thymol. The sampling times in this study were selected to best represent the hypothesized elimination curve of a semivolatile compound.

Phyto-Mast contains 4 essential plant oils in a canola oil base. Each of these essential oils is made up of many different chemicals. In our assay, we were able to identify one major chemical from one of those essential oils in milk and plasma from animals treated with intramammary infusions of the product. However, our research efforts do not provide information about the elimination of other chemicals from the body.

This study used lactating goats as a cost-effective model for estimating elimination kinetics in dairy cattle. Previous studies have reported that elimination of substances delivered by intramammary injection can be more rapid, similar, or slower than the same 


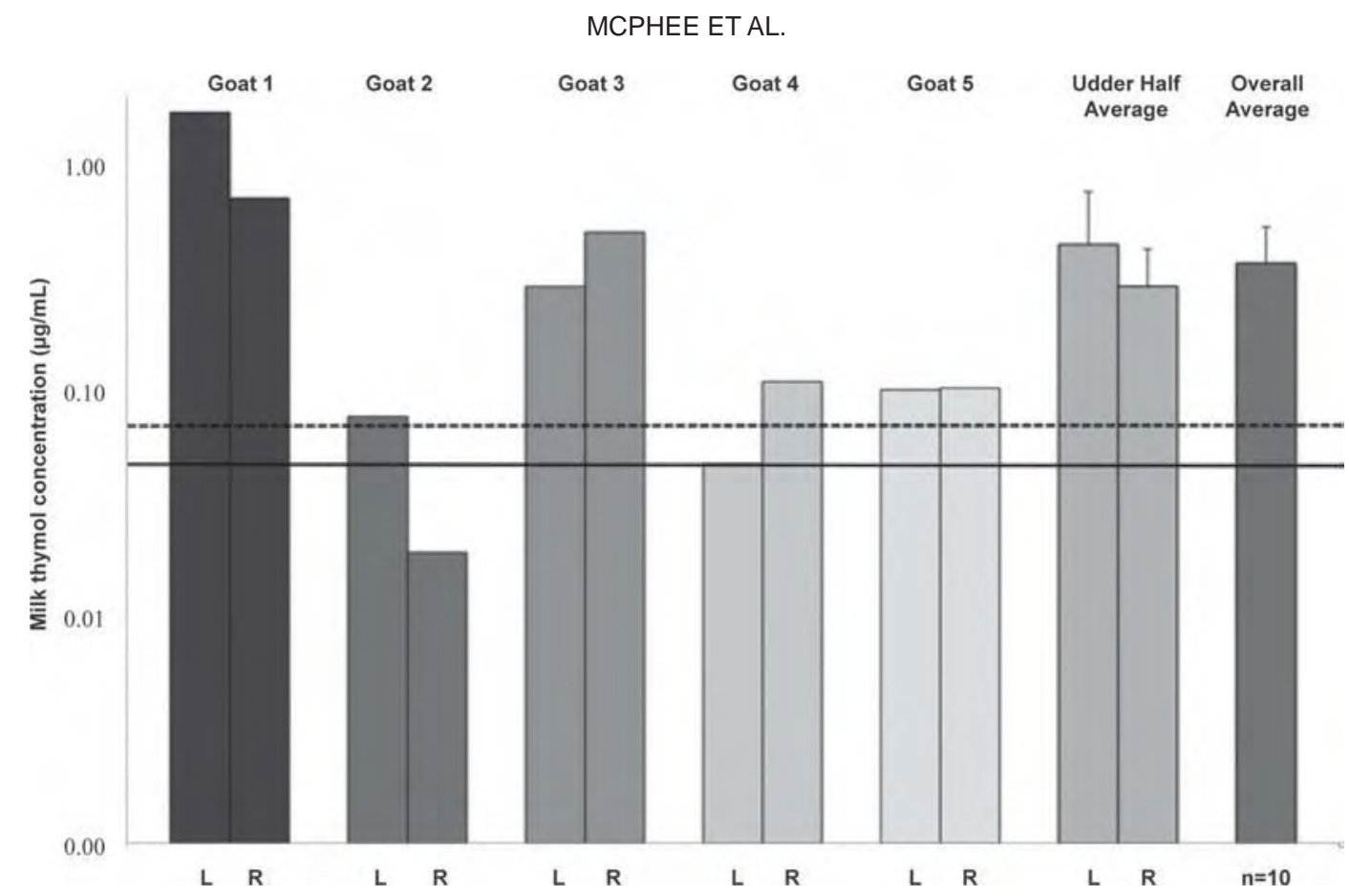

Figure 2. Milk thymol concentration by udder half, 12-h postintramammary phytoceutical administration milking (logarithmic scale). The milk thymol concentration in parts per million is shown for each individual animal and separated by udder halves (left udder on the left, right udder on the right) at the 12 -h posttreatment milking. The solid line indicates the limit of detection $(0.05 \mu \mathrm{g} / \mathrm{mL})$ and the dotted line represents the limit of quantification $(0.075 \mu \mathrm{g} / \mathrm{mL})$. Only the 12 -h posttreatment milk samples had detectable thymol concentrations. The average for all 5 left and right udders is shown, as well as the overall average in the last column.

substance in the bovine (Long et al., 1984; Buswell et al., 1989; Karzis et al., 2007). Another study examining the elimination of flunixin by oral, intramuscular, and intravenous routes of administration found very similar pharmacokinetics in goats and cattle (Königsson et al., 2003). We conclude that in the absence of pharmacokinetic data in cattle, gathering pilot data in dairy goats allows a useful preliminary assessment of Phyto-Mast elimination in lactating ruminants.

We dosed the phytoceutical product using roughly one-half of a prepared tube intended for treatment of one quarter of a dairy cow's udder. This decision was made based on the smaller size of the goat (roughly $1 / 10$ the weight of a Holstein cow), in addition to the fact that producers usually treat an animal with either a full tube or a half tube of treatment. Our study infused $10 \mathrm{~mL}$ total per goat, whereas a cow would have received approximately $12 \mathrm{~mL}$ in the affected quarter.

Our current work does not address the product's efficacy. Phyto-Mast has recently been examined in a research dairy as a dry-off treatment compared with conventional dry cow antibiotics used with a teat sealant and with no dry-off treatment. Phyto-Mast was found to be less effective than the conventional treatment but more effective than no treatment in preventing new infections during the dry period (Mullen et al., 2010).
This research, using the headspace technique with GC-MS, expands the possibilities for future work examining herbal mastitis treatments at labeled dosages and in dairy cows. Although most of the residues detected were often below the LOQ, we demonstrated the ability to detect low concentrations of thymol present in milk and plasma samples following IMM administration.

Based upon the absence of any systemic or local response to IMM infusion of the phytoceutical and the absence of any change in the CMT, we conclude that the phytoceutical product was not irritating. Additionally, our repetition of the CMT and aseptically collected milk cultures indicates that the product did not lead to inflammation in the udder or to bacterial growth.

These findings provide a framework and an analytical method for examining the pharmacokinetic behavior of an IMM phytoceutical mastitis treatment. In the future, we would like to build on this work in several ways. Quantifying thymol residues in cattle given the dose recommended by the manufacturer $(12 \mathrm{~mL}$ per quarter for 4 consecutive milkings) would provide valuable information about the product's elimination in cattle. Additionally, developing assays to detect the pharmacokinetics of the main chemicals in the other Phyto-Mast ingredients, such as glycyrrhizin and methyl salicylate, will allow for a more accurate estimate of 
a withdrawal time for this and related intramammary phytoceuticals.

\section{ACKNOWLEDGMENTS}

We thank Tabatha Wilson at the North Carolina State University (NCSU) Metabolism Educational Unit, the staff of the NCSU Center for Chemical Toxicology Research and Pharmacokinetics, and Roberta Lyman of the Mastitis and Milk Microbiology Laboratory (NCSU, Raleigh). This project received support from the George H. Hitchings New Investigator Award through the Burroughs Wellcome Fund (Research Triangle Park, NC), and from the USDA Food Animal Residue Avoidance Databank (FARAD, NCSU, Raleigh). Goats and care were supported in part by a donation from Hubert E. and Rebekah Karreman of Penn Dutch Cow Care, Narvon, Pennsylvania (developer and distributor of Phyto-Mast).

\section{REFERENCES}

Buswell, J. F., C. H. Knight, and D. M. Barber. 1989. Antibiotic persistence and tolerance in the lactating goat following intramammary therapy. Vet. Rec. 125:301-303.

Hogan, J. S., R. N. González, R. J. Harmon, S. C. Nickerson, S. P. Oliver, J. W. Pankey, and K. L. Smith. 2005. Laboratory Handbook on Bovine Mastitis. Revised ed. 2005. NMC, Verona, WI.

International Federation of Organic Agriculture Movements. 2008. The World of Organic Agriculture: Statistics and Emerging Trends
2008. International Federation of Organic Agriculture Movements, Bonn, Germany.

Karreman, H. J. 2007. Treating dairy cows naturally: Thoughts and strategies. Acres USA, Austin, TX.

Karzis, J., E. F. Donkin, and I. M. Petzer. 2007. Withdrawal periods and tissue tolerance after intramammary antibiotic treatment of dairy goats with clinical mastitis. Onderstepoort J. Vet. Res. $74: 281-288$.

Kentucky State University Organic Agricultural Working Group. 2009. Approved Medicines for Organic Livestock. Accessed February 9, 2011. http://organic.kysu.edu/Medicines.shtml.

Königsson, K., K. Torneke, I. V. Engeland, K. Odensvik, and H. Kindahl. 2003. Pharmacokinetics and pharmacodynamic effects of flunixin after intravenous, intramuscular and oral administration to dairy goats. Acta Vet. Scand. 44:153-159.

Long, P. E., J. E. Heavner, G. Ziv, J. N. Geleta, and K. Nepote. 1984. Depletion of antibiotics from the mammary gland of goats. J. Dairy Sci. 67:707-712

Mullen, K. A. E., K. L. Anderson, and S. P. Washburn. 2010. Effectiveness of an herbal remedy compared to control or traditional therapy in dry off treatments. J. Dairy Sci. 93(E-Suppl. 1):81. (Abstr.)

Ruegg, P. L. 2009. Management of mastitis on organic and conventional dairy farms. J. Anim. Sci. 87(E. Suppl.):43-55.

Snyder, L. R., J. J. Kirkland, and J. L. Glajch. 1997. Practical HPLC Method Development. 2nd ed. Wiley, New York, NY.

USDA-Agricultural Marketing Service. 2010. Database on NOSB Recommendations for Materials Considered for Use in Organic Agricultural Production and Handling. USDA, Washington, DC.

USDA-Agricultural Marketing Service National Organic Program. 2008. Organic Production and Handling Standards. USDA, Washington, DC.

Vijay, V., J. Yeatts, J. Riviere, and R. Baynes. 2007. Predicting dermal permeability of biocides in commercial cutting fluids using a LSER approach. Toxicol. Lett. 175:34-43.

Wynn, S. G., and B. Fougère. 2007. Veterinary Herbal Medicine. Mosby Elsevier, St. Louis, MO. 